\title{
CLINICAL PRESENTATION AND TREATMENT OUTCOME IN PATIENTS PRESENTING WITH FOREIGN BODY IN EAR, NOSE AND THROAT- A THREE-YEAR TERTIARY HOSPITAL EXPERIENCE
}

\author{
Anil Markose Puthumanakunnel', Sajeev George ${ }^{2}$
}

${ }_{1}^{1}$ Associate Professor, Department of ENT, MOSC Medical College Hospital, Kolenchery, Ernakulam, Kerala.

2Professor and HOD, Department of ENT, MOSC Medical College Hospital, Kolenchery, Ernakulam, Kerala.

\section{ABSTRACT}

\section{BACKGROUND}

In Otorhinolaryngology, foreign bodies in ear, nose and throat is a commonly encountered emergency. Timely and skilful intervention averts any complication that may arise due to the foreign body or its removal.

The aim of the study is to evaluate the patients' characteristics, their presentation, mode of treatment, the site, type and frequency distribution of the foreign bodies in ear, nose and throat.

\section{MATERIALS AND METHODS}

All patients presenting with history of foreign body in ear, nose and throat during the period of three years from July 2014 constituted the study. History, symptoms and signs of patients, time interval between presentation and their removal, along with method of treatment and characteristics of foreign body were recorded.

\section{RESULTS}

Majority of the patients with foreign body in ear, nose and throat were below 10 years of age. $90 \%$ of the patients presented within a day of foreign body ingestion or insertion. Most of them were managed on an outpatient basis. Animate foreign bodies like insects were common in the ear while seeds and fish bone were seen in the nose and throat respectively.

\section{CONCLUSION}

Foreign bodies in ear, nose and throat is an emergency that necessitates an experienced otorhinolaryngologist with well-equipped facilities to keep complications minimal.

\section{KEYWORDS}

Foreign Body, Ear, Nose, Throat, Otorhinolaryngology.

HOW TO CITE THIS ARTICLE: Puthumanakunnel AM, George S. Clinical presentation and treatment outcome in patients presenting with foreign body in ear, nose and throat- A three-year tertiary hospital experience. J. Evolution Med. Dent. Sci. 2018;7(02):146-148, DOI: 10.14260/jemds/2018/32

\section{BACKGROUND}

Foreign bodies in ear, nose and throat is a frequently encountered emergency in day-to-day practice. Undiagnosed foreign bodies over a period of time have varied presentation making it a diagnostic and therapeutic dilemma.

A foreign body is any object in the body which normally does not belong there. Bresslar in his work stated that $11 \%$ of emergencies in Otorhinolaryngology casualty were foreign bodies.[1] Ear, nose and throat are the most common sites of foreign body lodgement. Each region has its own distinct presentation and removal at times pose difficulty to even a specialist.

Foreign body lodgement may be accidental or voluntary. In children, numerous reasons have been attributed, a few being an attempt to explore his or her surroundings by putting things into their mouth, ear and nose. $[2,3]$

Varied presentations of foreign bodies in ear, nose and throat were noted over the years, the most common being foul smelling nasal or ear discharge, throat pain and some

'Financial or Other Competing Interest': None.

Submission 27-11-2017, Peer Review 22-12-2017,

Acceptance 28-12-2017, Published 08-01-2018.

Corresponding Author:

Dr. Anil Markose Puthumanakunnel,

Associate Professor, Department of ENT,

MOSC Medical College Hospital,

Kolenchery-682311, Ernakulam, Dist. Kerala, India.

E-mail: yoursonlyanilmark@gmail.com

DOI: $10.14260 /$ jemds $/ 2018 / 32$

\section{(c) (i) $($ ) $\ominus$}

may even present with complications. These complications may be due to previous failed attempts at removal or lack of skill or instruments for removal.

Foreign body lodgement site and duration can be an important factor in determining the expertise needed in removing it. Foreign body removal technique varies depending on age of patient, site and duration of foreign body along with its relationship to the vital structures. ${ }^{[4]}$ Hence, the need for a study to ascertain the patient demography, their presentation and foreign body characteristics in patients with foreign bodies in ear, nose and throat.

The aim of this study was to evaluate the patients characteristics, their presentation, mode of treatment, the site, type and frequency distribution of the foreign bodies in ear, nose and throat.

\section{MATERIALS AND METHODS}

Patients who presented with history of foreign body in ear, nose and throat to the Department of Otorhinolaryngology at MOSC Medical College Hospital, Kolenchery during the period of three years i.e. from July 2014 to June 2017 constituted the study. This cross-sectional study was done retrospectively by studying the charts of patients who presented to our department with a history of foreign body in ear, nose and throat.

All patients irrespective of age presenting to this tertiary care hospital with a clinical diagnosis of foreign body in ear, nose, and throat were included in this study. Patients presenting with history suggestive of foreign body aspiration, 
or lodgement as a result of injuries or during surgeries were excluded from this study.

History, presenting symptoms and signs of patients with a clinical diagnosis of foreign body in ear, nose and throat were recorded. Time between insertion of foreign bodies and their presentation was noted. Modality of treatment with characteristics of foreign body removed were recorded. Radiology investigations like X- ray was done only when the foreign body was not visible. Procedures involved in foreign body removal: evaluation under microscope, fibre-optic laryngoscopy, direct laryngoscopy, oesophagoscopy, and hypopharyngoscopy were noted. Instruments for extraction of foreign body ranged from Crocodile micro ear forceps, Right angled hook, suction, Jobson Horne wax probe, Rose Eustachian tube catheter, Tilley's nasal forceps, Lack's tongue depressor and foreign body removal forceps. Complications due to the foreign body or its manipulation if any, were also noted.

Data was entered in MS excel and analysed using SPSS. Results of the analysis were expressed in proportions and percentages.

The study was approved by the Institutional Ethical Committee of MOSC Medical College \& Hospital, Kolenchery.

\section{RESULTS}

Of the 288 cases in our study, 115 and 107 were ear and nose foreign bodies respectively while the remaining 66 cases were throat foreign bodies. Majority of patients who presented with foreign body in ear, nose and throat were in the age group below 10 years of age (Figure-1).

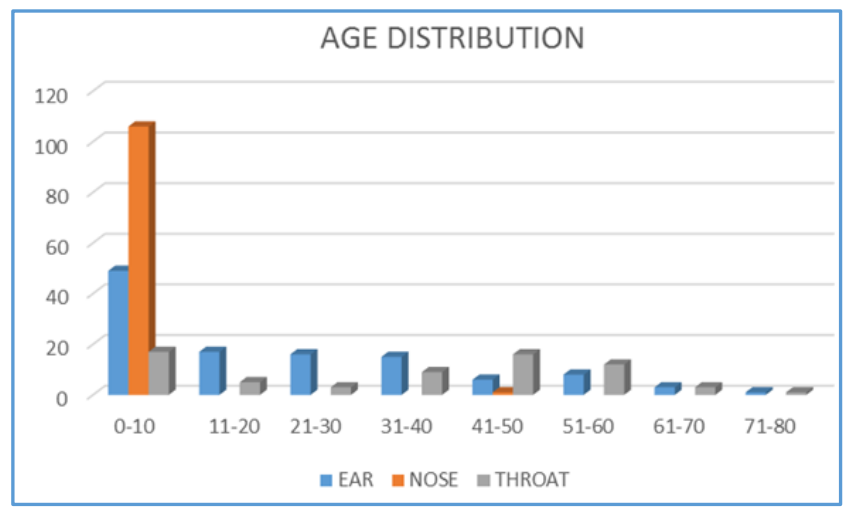

Figure 1. Age wise Distribution of Foreign Bodies

Foreign body incidence was more among males compared to female patients. History of foreign body insertion/impaction was obtained in $93 \%$ of cases. Majority of the patients i.e. $90 \%$ presented within a day of the foreign body insertion/impaction. It was seen in our study that most of the foreign bodies of ear and nose were managed on an outpatient basis unlike throat foreign bodies which required general anaesthesia. Evaluation under microscope was a common procedure technique for removal of ear foreign bodies while anterior rhinoscopy and oesophagoscopy were required in nose and throat foreign bodies respectively. Among the ear foreign bodies, animate objects like insects were the commonest. Vegetative matter like seeds constituted the majority in the nasal foreign bodies. Fish bone followed by chicken bone impaction were noted commonly in throat cases (Figure-3).

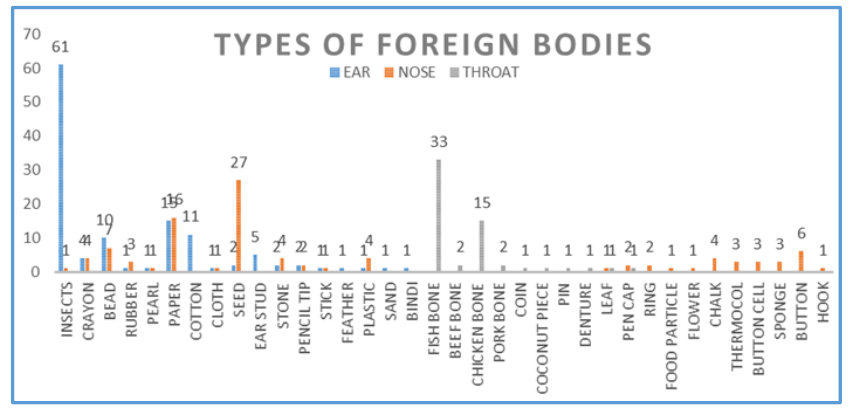

Figure 2. Type of Foreign Bodies

The most common ear involved was the right while it was the right nostril in nasal foreign bodies (Table-1). No foreign body was detected in 11 cases of our study. Right tonsil was the commonest site of impaction in throat cases.

\begin{tabular}{|c|c|c|}
\hline $\begin{array}{c}\text { Site of Foreign Body } \\
\text { Lodgement }\end{array}$ & $\begin{array}{c}\text { Number of } \\
\text { Cases }\end{array}$ & $\begin{array}{c}\text { Percentage } \\
(\%)\end{array}$ \\
\hline \multicolumn{3}{|l|}{ Ear } \\
\hline Right ear & 62 & 22 \\
\hline Left ear & 50 & 18 \\
\hline Both ears & 3 & 1 \\
\hline \multicolumn{3}{|l|}{ Nose } \\
\hline Right side & 57 & 20 \\
\hline Left side & 42 & 15 \\
\hline Both sides & 2 & 0.7 \\
\hline \multicolumn{3}{|l|}{ Throat } \\
\hline Right tonsil & 11 & 4 \\
\hline Left tonsil & 6 & 2.1 \\
\hline Posterior pharyngeal wall & 10 & 3.6 \\
\hline Tongue base & 8 & 2.9 \\
\hline Right pyriform fossa & 1 & 0.4 \\
\hline Left pyriform fossa & 5 & 1.8 \\
\hline Oesophagus -cricopharynx & 13 & 4.7 \\
\hline $\begin{array}{c}\text { Oesophagus -upper one } \\
\text { third }\end{array}$ & 7 & 2.5 \\
\hline
\end{tabular}

The commonly used instrument for extraction of ear foreign bodies was Crocodile micro ear forceps while Rose Eustachian tube catheter and foreign body removal forceps in nose and throat cases were used respectively. Out of the 288 cases studied, only $3.8 \%$ of the cases developed complications.

\section{DISCUSSION}

Foreign body in ear, nose and throat is a commonly encountered emergency in day-to-day otorhinolaryngology practice. Skilled and timely intervention is important to minimise complications. Foreign bodies in ear and nose are common among young children while throat foreign bodies are common in adults.

Our study confirmed the earlier findings of Banerjee et al[5] and Olajide et al[6] that children below the age of ten years were commonly associated with foreign bodies of ear and nose. This age group's curiosity to explore their surroundings for objects and their tendency to insert them into the natural accessible orifices like ear, nose and mouth might be an explanation. Nasal foreign bodies were commonly seen in children with cold, as they try to stop the irritating secretions dripping out by obstructing the nose with any foreign body. Likewise, ear foreign bodies were seen 
commonly in patients with itchy or discharging ear. Throat foreign bodies in elderly age group may be attributed to many factors which include being edentulous, having poor masticating habits and also with a mostly preoccupied mind while having food.

There was a predominance of male patients in our study which concurred with other authors.[7,8] Most of the cases presented within a day of foreign body ingestion/insertion similar to other studies,[6,9] which may have attributed to lesser complications in our study.

Detailed history is very important prior to any attempt to remove the foreign body. The characteristics of foreign body involved like shape, surface, size, number and colour may facilitate their removal. Any unskilled attempt to remove the foreign body should also be noted, in order to know whether the case is already complicated or not, like tympanic membrane perforation or accidental dislodgement of a nasal foreign body.[10] In our study, only four cases gave a history of failed attempt at removal outside the hospital.

Most of the foreign bodies of ear and nose in our study (78.9\%) were removed in outpatient department which agreed with Parajuli's work.[7]

Insect was the most common foreign body in the ear (50\%) followed by paper and cotton, differing with other studies.[11,10] This is probably due to the fact that our patients were mainly from a rural background with abundant rubber plantations infested with insects mainly beetles. Seeds were the commonest foreign body in the nose unlike Rodrigues et al findings. Fish bone impaction was common in the throat as fish being a local delicacy here and also signifies the need for more awareness and care while having them.

Commonest ear and nostril involved was the right, may be explained by right hand dominance in this population making easier to insert foreign bodies more on the right side. Throat foreign bodies in our study lodged more often in the tonsils, the reason may be due to their natural projection into the oral cavity, making their impaction more there.

Technique and instruments commonly employed for removal of foreign body in ear were Crocodile micro ear forceps under microscope and Rose Eustachian tube catheter by anterior rhinoscopy in nose similar to the various techniques described by Davis et al.[4] Complications caused by the foreign body presence or its removal was 3.8\% in our study which was far lower than what was seen in Magussi et al and Tiago et al studies.[12,13] This signifies the importance of proper decision making, instrumentation and most importantly experienced faculty in handling such cases.

\section{CONCLUSION}

Foreign body in ear, nose and throat is a commonly encountered problem in the emergency department. Ear and nose foreign bodies are common among children. Proper immobilisation with adequate instruments and facilities is the key to successful foreign body removal. Nasal and pharyngeal foreign bodies have a high potential for aspiration, so they should be referred at the earliest to an experienced otorhinolaryngologist.

\section{REFERENCES}

[1] Bressler K, Shelton C. Ear foreign-body: a review of 98 consecutive cases. Laryngoscope 1993;103(4 Pt 1):367-70.

[2] Reilly J, Thompson J, MacArthur C, et al. Pediatric aerodigestive foreign body injuries are complications related to timeliness of diagnosis. Laryngoscope 1997;107(1):17-20.

[3] Shrestha I, Shrestha BL, Amatya RCM. Analysis of ear, nose and throat foreign bodies in Dhulikhel hospital. Kathmandu Univer Med J 2012;10(38):4-8.

[4] Davies PH, Benger JR. Foreign bodies in the nose and ear: a review of techniques for removal in the emergency department. J Emergency Medicine 2000;17(2):91-4.

[5] Banerjee S. Concept of foreign body - it's past and present. Indian J Otolaryngol Head Neck Surg 1999;51(Suppl 1):23-30.

[6] Olajide TG, Ologe FE, Arigede 00. Management of foreign bodies in the ear: a retrospective review of 123 cases in Nigeria. Ear Nose Throat J 2011;90(11):E16-9.

[7] Parajuli R. Foreign bodies in the ear, nose and throat: an experience in a tertiary care hospital in central Nepal. Int Arch Otorhinolaryngol 2015;19(2):121-3.

[8] Ologe FE, Dunmade AD, Afolabi OA. Aural foreign bodies in children. Indian J Pediatr 2007;74(8):755-8.

[9] Hon SK, Izam TM, Koay CB, et al. A prospective evaluation of foreign bodies presenting to the Ear, nose and throat clinic, Kuala Lumpur Hospital. Med J Malaysia 2001;56(4):463-70.

[10] Rodrigues FR, Aparacide AA, Avila KAO, et al. Complications of ENT foreign bodies; a retrospective study. Bras J Otorhinolaryngol 2008;74(1):7-15.

[11] Ray R, Dutta M, Mukherjee M, et al. Foreign body in ear, nose and throat: experience in a tertiary hospital. Indian J Otolaryngol Head and Neck Surg 2014;66(1):13-16

[12] Mangussi-Gomes J, Andrade JS, Matos RC, et al. ENT foreign bodies: profile of the cases seen at a tertiary hospital emergency care unit. Braz J Otorhinolaryngol 2013;79(6):699-703.

[13] Tiago RSL, Salgado DC, Correa JP, et al. Foreign body in ear, nose and oropharynx: experience from a tertiary hospital. Braz J Otorhinolaryngol 2006;72(2):177-81. 